\title{
Rare Case report of Amyand's Hernia in a Premature Infant
}

\author{
Zohra Ashraf Siwji ${ }^{1}$, Alya Talib AlBlooshi ${ }^{2}$, Moustafa Hamchou ${ }^{2}$, Aiman Rahmani ${ }^{1}$ \\ ${ }^{1}$ Neonatal Intensive Care Unit, Tawam Hospital, Al Ain, United Arab Emirates. \\ ${ }^{2}$ Pediatric Surgery Department, Tawam Hospital, Al Ain, United Arab Emirates.
}

*Corresponding Author: Abdulwahab Alahmari, Radiology Specialist, Ministry of Health, Abha, Kingdom of Saudi Arabia.

Received Date: August 03, 2021 | Accepted Date: September 30, 2021 | Published Date: October 09, 2021

Citation: Zohra A Siwji, Alya T AlBlooshi, M Hamchou, A Rahmani. (2021). Rare Case report of Amyand's Hernia in a Premature Infant. International Journal of Clinical Case Reports and Reviews. 8(5); DOI:10.31579/2690-4861/160

Copyright: ( 2021 Aiman Rahmani, This is an open-access article distributed under the terms of the Creative Commons Attribution License, which permits unrestricted use, distribution, and reproduction in any medium, provided the original author and source are credited.

\begin{abstract}
:
Although inguinal hernias are a common finding in premature infants, it is usually caused by the protrusion of the bowel through a persistent patent processus vaginalis. However, acute appendicitis in association with an inguinal hernia in this age group is a rare finding. This type of hernia is referred to as an Amyand hernia.

Keywords: Amyand hernia; inguinal hernias; vaginalis; premature infants
\end{abstract}

\section{Introduction:}

Although inguinal hernias are a common finding in premature infants, it is usually caused by the protrusion of the bowel through a persistent patent processus vaginalis. However, acute appendicitis in association with an inguinal hernia in this age group is a rare finding. This type of hernia is referred to as an Amyand hernia [1].

Amyand's hernia is a term used to describe an inguinal hernia containing either a normal or inflamed vermiform appendix in an incarcerated inguinal hernia. It was first described in 1735 \& subsequently named after Claudius Amyand, after he successfully performed an appendectomy on an 11-year- old boy with the above presentation [1].

The incidence of finding a normal appendix within the inguinal hernia sac is narrated to be approximately $1 \%$ [3]. While to find an inflamed appendix is even less common \& accounts for only $0.08-0.13 \%$. Such cases are extremely rare in neonates \& infants due to the lack of detail available with only about 20 cases being reported so far in the literature [3].

Clinical presentation of this hernia can mimic that of an incarcerated or strangulated inguinal hernia therefore making it uncommon to be diagnosed preoperatively.

When looking at the cases of appendicitis, it is also extremely rare in the neonatal period with only $0.1 \%$ of cases being detected $\&$ has only been reported to occur in around $2 \%$ of the pediatric patients under the age of 12 months [1]. Of the $0.1 \%$ of the neonatal appendicitis, it has been noted that 1/3 of such cases are associated with Amyand's hernia [1].
In this article, we are reporting a case of a premature baby, part of twin, with Amyand's hernia, with an inflamed \& necrotic vermiform appendix within the sac of the right inguinal hernia.

We present this rare occurrence of Amyand Hernia in a 2-month old male, part of twin, born prematurely at 26 weeks' gestation, due to maternal placental abruption. The infant presented at the age of 5 weeks with a one-day history of abdominal distention, tenderness in addition to scrotal edema. There were no signs of peritonitis.

Radiologic studies of abdominal X-Ray (Figure 1) showed distended bowel with no free air \& non contractile loops.

Abdominal ultrasound was performed \& reported to have evidence of right inguinal hernia seen reaching the right hemi-scrotum, containing bowel loops with evidence of Doppler flow seen. The right testicle is not obviously seen. Unremarkable appearance of the left testicle (Figure 2).

The systemic examination was grossly normal. The clinical assessment made was that of a strangulated inguinoscrotal hernia. Sepsis screen was carried out \& patient was started on piperacillin/tazobactam \& Flucloxacillin; The blood test results showed a white cell count of $10.5^{9} / \mathrm{L}$, a haemoglobin of $136 \mathrm{~g} / \mathrm{L} \&$ platelet count of 281 . The urea \& electrolyte were within normal limits \& blood gas showed a normal lactate level.

The patient underwent Right groin exploration and diagnostic laparoscopy through the right hernia sac. The intraoperative findings included: strangulated right Inguinal hernia with necrotic appendix (Figure 3). Fortunately, there was no signs of intra-abdominal necrotic bowel. However, contralateral left indirect inguinal hernia was noted. Therefore, the patient underwent bilateral inguinal herniotomy \& appendectomy. 
The infant had an uneventful postoperative course with no further complications. Initially was started on TPN \& was commenced on feeds by post op day 5 , which the patient tolerated well with no complications. Patient completed a total of 5 days of antibiotics due to the intraoperative findings of incarcerated hernia with necrotic appendix, despite all inflammatory markers being benign.
The histopathology report (Figure 4) confirmed that the tissue is extensively necrotic and replaced by hemorrhage. Given the ghost of cord/tubular structure with focal lumen-like formation; the tissue may represent markedly congested and necrotic appendix.

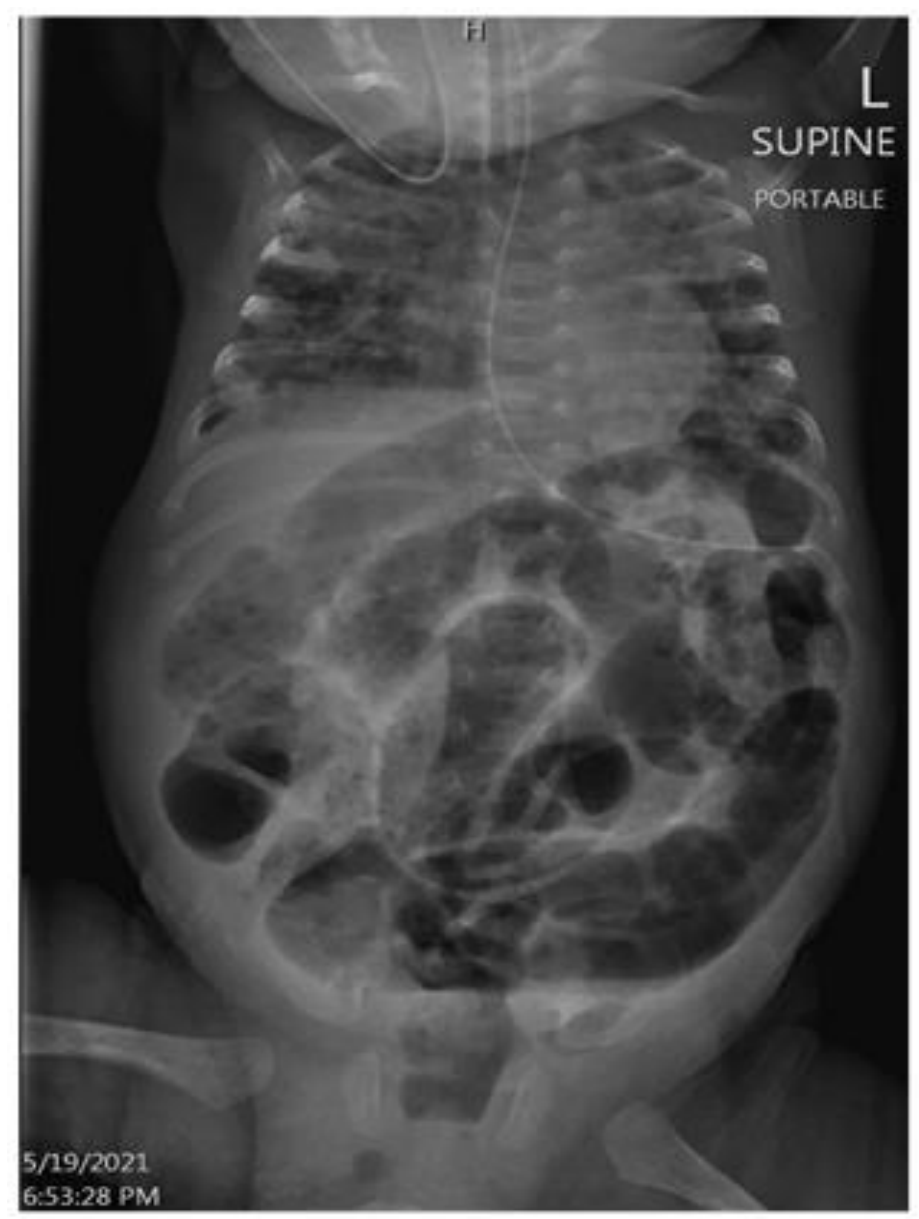

Figure 1: The small bowel loops are distended with air with colonic residue in the large bowel loops and air seen in the rectum. No pneumatosis intestinalis or portal venous gas. No pneumoperitoneum

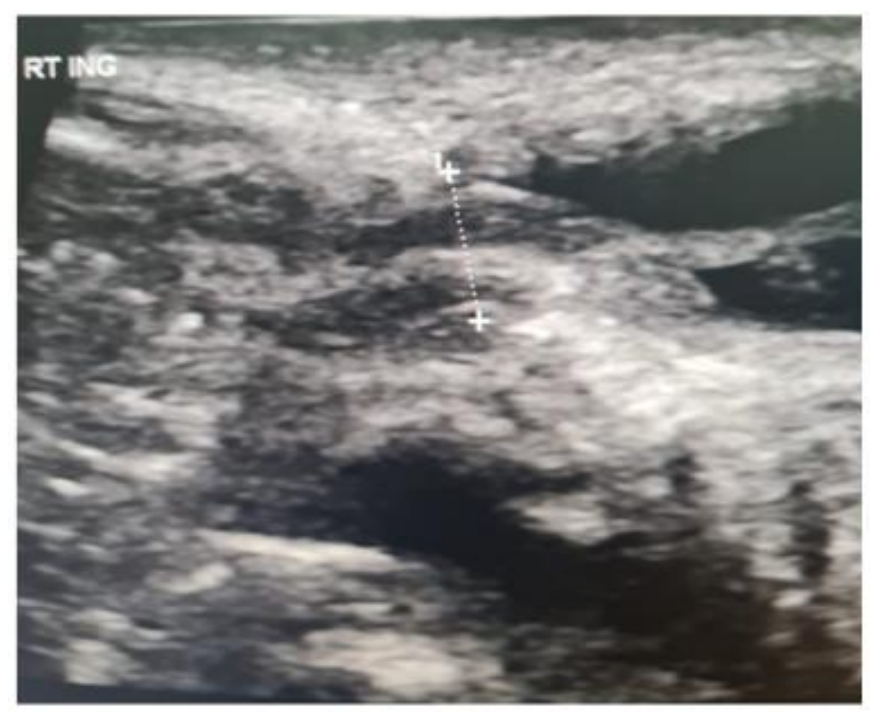

Figure 2: USG of the Right inguinal canal showing thickened appendix 


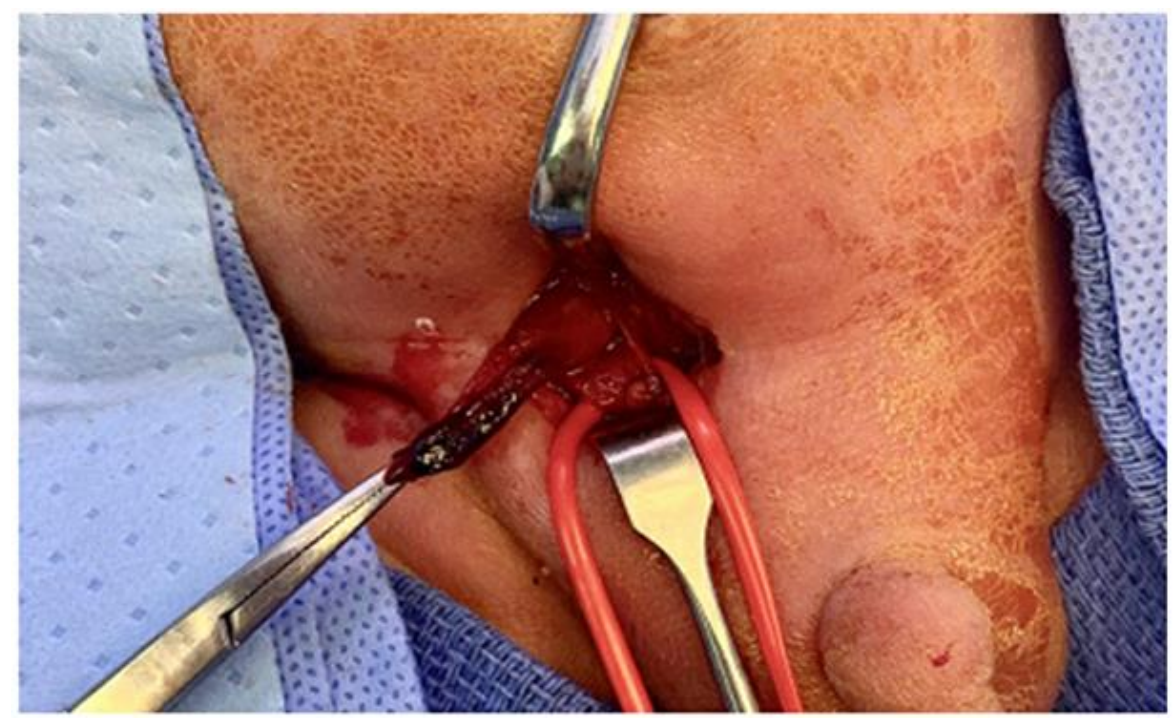

Figure 3: Right inguinal hernia with incarcerated necrotic appendix
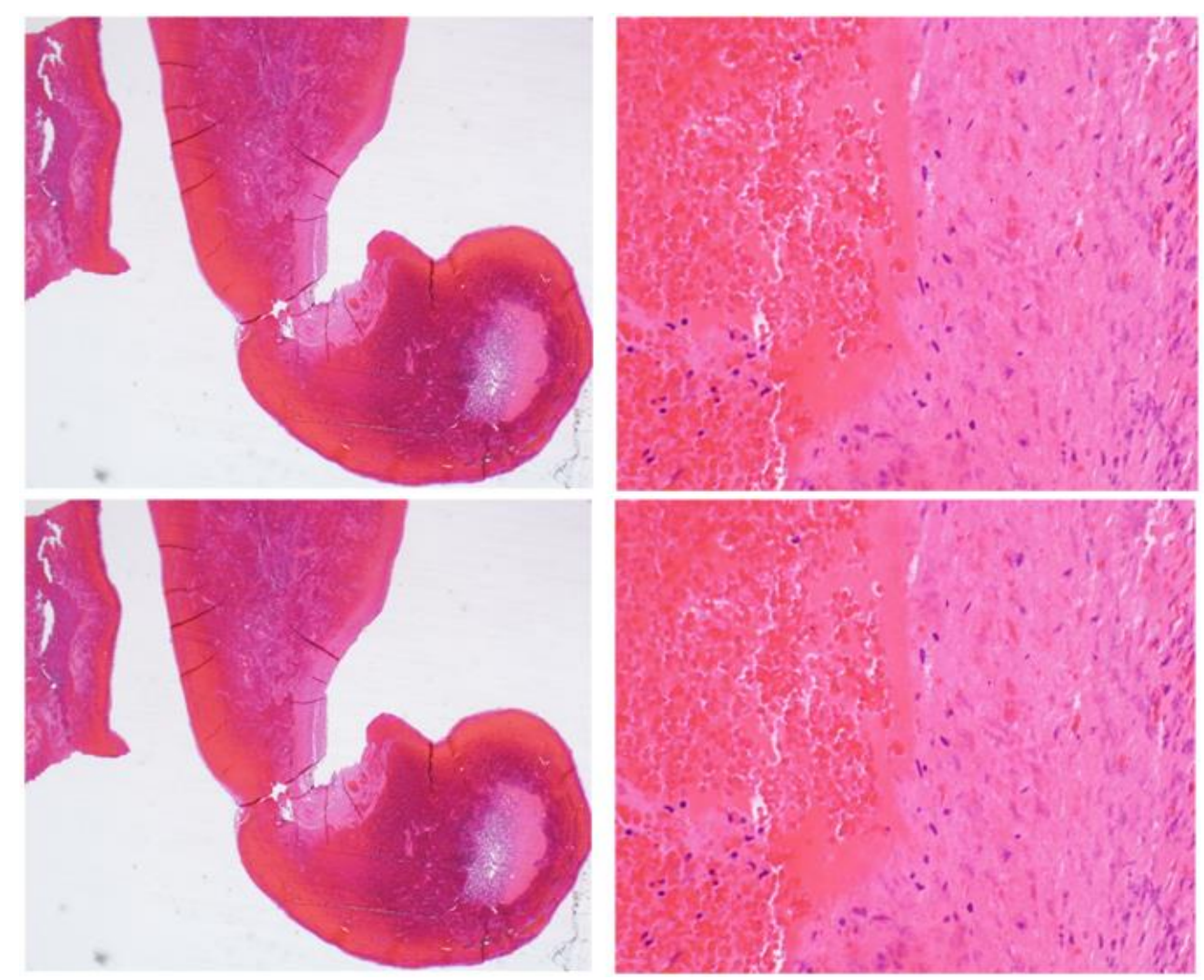

Figure 4: Section shows extensively necrotic cord/tubular like tissue (left image), on higher magnification there is extensive necrotic congested \& hemorrhagic tissue (right image).

\section{Discussion:}

A hernia is defined as the protrusion of an organ or part of an organ or fascia through connective tissue or through a wall of the containing cavity in which it is normally enclosed. The contents of an inguinal hernia usually include small bowel and omentum. The incidence of a normal appendix in an inguinal hernia is $1 \%$ and this drops further to $0.1 \%$ when looking at cases of inflamed or perforated appendices [2].
Although inguinal hernia is a common finding in premature neonates, with an incidence reaching up to $18 \%$, acute appendicitis in this age group is very rare. Acute appendicitis in infants occurs in $2 \%$ of pediatric appendicitis cases [3]. Neonatal appendicitis is extremely rare and represents $0.1 \%$ of all infantile cases [3]. It has been estimated that $50 \%$ of such cases are premature neonates, and in one-third of these the inflamed appendix lies within a hernia sac [3]. 
An Amyand's hernia has been implicated as a cause for neonatal appendicitis in 25-30\% of all cases reported in the literature [2]. The pathophysiology of Amyand's hernia is unknown and the relationship between incarceration and inflammation of the appendix has not been clarified. Some have raised the idea that Amyand's hernia with acute appendicitis could be an incidental finding while others suggest that there is a possible relationship between the incarceration of the appendix \& the subsequent inflammation [3]. Other theories that have been suggested were that the appendix becomes susceptible to trauma once it has entered the sac. Once in the sac the blood supply may be subsequently cut off or dramatically reduced stemming to the development of inflammation \& bacterial overgrowth. This can further be exacerbated with any increase in intra-abdominal pressure that would subsequently cause compression of the appendix, ischemia, bacterial overgrowth \& the final inflammation $\&$ the complications that may arise [3].

The presence of the appendix within the hernial sac is often an incidental finding during surgical intervention, because pre-operative diagnosis is extremely difficult with accepted imaging modalities in the setting of strangulated hernia and testicular torsion [1]. In addition, the diagnosis of Amyand's hernia is rarely on the differential for most clinicians due to lack of awareness of the condition [1].

The common clinical presentation of an Amyand's hernia is often of an incarcerated or strangulated hernia \& the diagnosis is usually confirmed intraoperatively [2]. Preoperative diagnosis is usually challenging \& difficult; imaging with ultrasound or even computed tomography scan can suggest the diagnosis but of course is not definitive [2]. However, due to the acute presentation $\&$ clinical findings patients are usually taken to the OR for emergency surgery ${ }^{2}$. In premature neonates, a painful swelling of the inguinoscrotal region, especially when accompanied by inflammation of the surrounding soft tissues, should lead to suspicion of Amyand's hernia [3].

\section{Management:}

The main stay of management is urgent surgical exploration of the inguinal region. Laparotomy may be considered in cases of possible peritoneal contamination [2].
Mortality rates in neonates \& infants are low as inguinoscrotal induration \& inflammation would usually lead to early surgical intervention [3]. Recent studies have demonstrated that laparoscopic surgery has become a preferred approach. This allows for a superior visualization of the entire abdominal cavity \& therefore become both diagnostic \& therapeutic2. Other benefits of laparoscopic versus open Amyand's hernia repair includes decreased postoperative pain \& earlier discharge [4].

\section{Conclusion:}

In conclusion, appendicitis within Amyand's hernia is extremely rare in neonates. It may be misdiagnosed as strangulated inguinal hernia, which is also managed in the same way of a surgical emergency. Therefore, it should also be considered as a differential diagnosis of strangulated inguinal hernia in premature neonates. The most optimal treatment is the urgent surgical exploration of the inguinal region. Appendectomy \& hernial repair can be carried out concurrently through the inguinal exploration.

\section{References:}

1. Patel S, McKee J, Maxwell J. (2020). Amyand's hernia with perforated appendicitis complicated by post-operative bowel Necrosis in an extremely preterm infant. Journal of Pediatric Surgery Case Reports. 59; 101486.

2. Pillay K, Gonzalez V, Rangaka T. (2018). A case of Amyand's hernia in a preterm infant. S Afr J Surg. 56(3).

3. E Livaditi G. Mavridis G. (2007). Christopoulos-Geroulanos Amyand's hernia in premature neonates: report of two cases. Hernia, 11(6); 547-549.

4. Park J, Hemani M, Milla S, Rivera R, Nadler E, Alukal J. (2010). Incarcerated Amyand's hernia in a premature infant associated with circumcision: a case report and literature review. Hernia. 14(6); 639-642.

5. Losanoff JE, Basson MD. (2007). Amyand hernia: what lies beneath--a proposed classification scheme to determine management. Am Surg. 73(12):1288-1290.

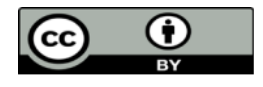

This work is licensed under Creative Commons Attribution 4.0 License

To Submit Your Article Click Here: Submit Manuscript

DOI: $10.31579 / 2690-4861 / 160$

\author{
Ready to submit your research? Choose Auctores and benefit from: \\ $>$ fast, convenient online submission \\ $>$ rigorous peer review by experienced research in your field \\ $>$ rapid publication on acceptance \\ $>$ authors retain copyrights \\ $>$ unique DOI for all articles \\ $>$ immediate, unrestricted online access
}

At Auctores, research is always in progress.

Learn more auctoresonline.org/journals/international-journal-of-clinicalcase-reports-and-reviews 